\title{
Impact of vitamin $D$ deficiency on health with regard to kidney disease; an updated mini-review
}

\author{
Nozar Dorestan ${ }^{1}$, Sara Bahadoram², Mohammad Bahadoram ${ }^{3}$, Mohammadreza Khosravi ${ }^{3}$, Mohammad \\ Davoodi ${ }^{4}$, Ali Hasanpour Dehkordi ${ }^{5}$, Zaher Khazaei ${ }^{6}$, Masoud Amiri ${ }^{7,8^{*}}$
}

${ }^{1}$ Department of Surgery, School of Medicine, Ahvaz Jundishapur University of Medical Sciences, Ahvaz, Iran ${ }^{2}$ Department of Pediatrics, Imam Khomeini Hospital Complex, Tehran University of Medical Sciences, Tehran, Iran ${ }^{3}$ Cancer Prevention Research Center, Isfahan University of Medical sciences, Isfahan, Iran

${ }^{4}$ Department of Radiology, School of Medicine, Ahvaz Jundishapur University of Medical Sciences, Ahvaz, Iran

${ }^{5}$ School of Allied Medical Sciences, Shahrekord University of Medical Sciences, Shahrekord, Iran

${ }^{6}$ Department of Public Health, School of Health, Sabzevar University of Medical Sciences, Sabzevar, Iran

${ }^{7}$ Social Determinants of Health Research Center and Department of Epidemiology and Biostatistics, Shahrekord University of Medical

Sciences, Shahrekord, Iran

${ }^{8}$ Department of Epidemiology, Erasmus Medical Center, Rotterdam, the Netherlands

\section{A R T I C L E I N F O}

Article Type:

Mini-Review

\section{Article History:}

Received: 20 November 2017

Accepted: 13 February 2018

ePublished: 10 March 2018

\section{Keywords:}

Vitamin D deficiency

Kidney diseases

Cancer

Cardiovascular diseases

Sunlight

Chronic kidney disease

\begin{abstract}
A B S T R A C T
Vitamin D or cholecalciferol, as a steroidal hormone, regulates the calcium homeostasis, and bone formation with reabsorption through kidneys, parathyroid glands and bowel. There are at least 800 human genes connected with vitamin D. Previous research has confirmed the relationship between vitamin $\mathrm{D}$ and colorectal cancers, infections, heart diseases, multiple sclerosis (MS), bone disorders, inflammatory and autoimmune diseases, inflammatory bowel diseases, diabetes mellitus type-I and II and also progression of kidney disease. However, the relationship of vitamin D deficiency and developing of breast cancer, rheumatoid arthritis and osteoporosis is unknown. In fact, the effect of vitamin D deficiency on pathogenesis of different diseases is controversial. To cope with vitamin D deficiency, there are different recommendations such as daily intake of vitamin D supplements and more exposure to sunlight.
\end{abstract}

\section{Implication for health policy/practice/research/medical education:}

Vitamin D deficiency was only limited to rickets in children and bone related disorders in adults in the past. However, nowadays it has also been associated with the pathogenesis and/or progression of many other diseases such as hypertension, multiple sclerosis (MS), diabetes, cancer, and renal disease. Despite this close relationship of vitamin D deficiency with human diseases, vitamin D insufficiency is not widely recognized as a problem by people, especially patients and physicians as well as health policy makers. It is recommended to conduct further studies on this association to clarify the exact effect of vitamin D deficiency as well as supplement therapy with vitamin $\mathrm{D}$ on human diseases.

Please cite this paper as: Dorestan N, Bahadoram S, Bahadoram M, Khosravi MR, Davoodi M, Hasanpour Dehkordi A, Khazaei $Z$, et al. Impact of vitamin D deficiency on health with regard to kidney disease; an updated mini-review. J Nephropharmacol. 2017;7(2):55-60.

\section{Introduction}

Vitamin D ( cholecalciferol), is a hormone with steroidal structure, regulates the calcium homeostasis, and bone formation with reabsorption through kidneys, parathyroid glands and bowel (1). There are many studies regarding the reported association between vitamin
$\mathrm{D}$ and various diseases and their treatment as well as health maintenance mentioning the high prevalence of vitamin $\mathrm{D}$ deficiency, most of them because of diet as well as other potential reasons such as low exposure to sunlight (2). In addition, there are at least 800 human genes connected with vitamin D (3). In fact, vitamin D 
has many substantial roles in many vital processes such as cellular growth and differentiation, metabolism of calcium, bones, cardiovascular and immunity functions (4). For example, it has been confirmed that vitamin D can prevent rickets and osteomalacia and may have an influence on immune modulatory, anticancer and innate immune through vitamin D receptor (5). Moreover, vitamin $\mathrm{D}$ is vital for function of muscles through affecting on muscle metabolism (6). The main potential risk factors for vitamin D deficiency may include age more than 65 (7), obesity (8), kidney disease (9), liver disease (10) and environmental factors such as frailty, decrease outdoor physical activity and institutionalization (11). However, the effect of vitamin $\mathrm{D}$ deficiency on pathogenesis of various illness is controversial (12).

In the 1980s, Barker et al reported that low-birth weight in early life could lead to coronary heart diseases later in life (13). In fact, vitamin D can play a substantial role in the development of fetal organs such as brain, lungs and bone which has been supported by experimental studies; it is recommended that until conducting more studies in this regard, using the vitamin D supplement by pregnant women could be very helpful (14). In addition, previous research has confirmed the relationship between vitamin $\mathrm{D}$ and colorectal cancers, infections, heart diseases, multiple sclerosis, bone disorders, inflammatory and autoimmune diseases, inflammatory bowel diseases, diabetes mellitus type-I and II; however, the association of vitamin D deficiency and developing of breast cancer, rheumatoid arthritis and osteoporosis is unknown (15).

\section{Materials and Methods}

The databases of PubMed/Medline, EBSCO, EMBASE, Web of Science, directory of open access journals (DOAJ), Scopus, and Google Scholar were searched with keywords of vitamin D deficiency, kidney diseases, cancer, cardiovascular diseases, sunlight, chronic kidney disease, end-stage renal disease, hemodialysis, hypertension, allcause mortality, diabetes mellitus, cholecalciferol, left ventricular hypertrophy, proteinuria, insulin resistance, inflammation, albuminuria and Sunlight.

\section{Vitamin D deficiency in general}

The relationship between vitamin $\mathrm{D}$ deficiency and different diseases have been reported in many studies, both observational and randomized trials (16). It has also reported that lower vitamin $\mathrm{D}$ consumption during pregnancy or early childhood could increase the risk of wheezing and asthma in later childhood and the offspring, respectively (17). The linkage between vitamin $\mathrm{D}$ and many health conditions have been investigated such as cardiovascular diseases (18), cancer (19), metabolic disorders and diabetes (20), early age at menarche (21), multiple sclerosis (MS) (22) and mortality (23). However, despite these relationships, the clear role of vitamin $\mathrm{D}$ is not known yet (16). Vitamin D could also play an important role in periodontal disease by maintaining oral health via its potential effects on metabolism of minerals and bones as well as innate immunity (5). If these relationships are causal, it would highlight the importance of vitamin D deficiency for public health, especially among residents of high latitudes or people who prefer lifestyles of indoor-oriented (24).

\section{Vitamin D deficiency and kidney}

The kidney is the main organ involving in the production of bioactive forms of vitamin D (25). Vitamin D could also play an important role in the survival of chronic kidney disease (CKD) and end-stage renal disease patients regardless of dialysis situation (26). CKD with or without hemodialysis could be considered as an independent risk factor for cardiovascular, progression of hypertension and all-cause mortality (27). In addition, it has been reported that vitamin $\mathrm{D}$ deficiency is prevalent in CKD patients. It may have a substantial role in mortality and morbidity related to CKD (28). Additionally, CKD can be considered as a risk factor for the development of vitamin D deficiency (25). There are also various non-skeletal actions of vitamin $\mathrm{D}$ such as immune modulation, anti-inflammatory actions and endothelial protection. Likewise, vitamin $\mathrm{D}$ deficiency may associate with many conditions like left ventricular hypertrophy, proteinuria, atherogenicity, insulin resistance, decreased thrombolysis, susceptibility to infections, perpetuation of inflammation and immune imbalances (28). Generally, the decline of albuminuria would be the main target in renoprotective-based therapy with extra help of vitamin D supplementation (29).

\section{Vitamin D deficiency and lung diseases}

For lung diseases, vitamin D deficiency could lead to chronic airway disease as well as systemic inflammation, increasing the risk of infections and reducing bacterial clearance simultaneously (30). Hushmand et al reported that higher vitamin $\mathrm{D}$ concertation has been correlated with better lung function through better measured forced expiratory volume in one second (FEV1) measurement (31). There is also an association between epidemic influenza and vitamin D deficiency (32). In addition, there was a dose-response relationship between serum vitamin D and forced expiratory volume (FEV1) without any statistically significant association (33). Moreover, vitamin $\mathrm{D}$ deficiency has been correlated with increasing risk of respiratory infection from influenza $\mathrm{A}$ and mycobacterium tuberculosis, cystic fibrosis, chronic obstructive pulmonary disease (COPD), interstitial lung disease, asthma and respiratory infections (34). Since COPD patients may have a high prevalence of vitamin $\mathrm{D}$ deficiency (ranging from $30 \%$ to more than $75 \%$ ) (35), many studies have been conducted to assess this association; for example, in a study in Turkey, it has been reported that COPD patients with vitamin D deficiency had poor balance, less muscle strength and severe physical 
functioning as well as severe disturbed lung and peripheral muscle functions (36). On the contrary, in another study, there was no significant relationship and monthly consumption of vitamin D supplement was detected. They found no benefits of administration of vitamin D therapy in COPD patients (37). Moreover, inactivity, absence of sun exposure, lower food intake, reduced capacity of skin for synthesis of vitamin D and glucocorticoids resulting in increased catabolism could contribute vitamin D deficiency to COPD patients (38). In another study, it was reported that exercise capacity and lung function did not improve using vitamin $\mathrm{D}$ supplementation in COPD patients (39). It should be noted that many questions regarding the impact of vitamin D deficiency on pulmonary function or structure, especially chronic pulmonary disease still exist. Therefore, further studies should be conducted about the direct/indirect effects of vitamin $\mathrm{D}$ on mechanisms of lung function and lung injury as well as clarifying potential benefits of vitamin D supplementation to preclude or handle of chronic lung disease (40).

Various studies have also shown that the incidence of vitamin D deficiency would be high in ear, nose and throat diseases (ENT) and also otolaryngological diseases. Thus promising results for the administration of vitamin $\mathrm{D}$ supplementation in patients with pharyngitis, upper respiratory tract infections with asthma, post-operation of chronic suppurative otitis media, mastoidectomy and cholesteatoma spread was existed (41).

\section{Cardiovascular diseases and vitamin D deficiency}

Cardiovascular diseases (CVDs) are the first cause of death worldwide (42). Their substantial risk factors are smoking, older age, diabetes, obesity, hypertension, dyslipidemia, physical inactivity, metabolic syndrome, a family history and personal history (43). However, there are still some patients who their disease cannot be explained by above mentioned risk factors (44). The potential mechanism of effect of vitamin D on maintenance of normal cardiovascular activity could be through the capability of this hormone (vitamin D) to control of blood pressure, reduce the risk of thrombosis, support cardiovascular contractility and prevent cardiac and blood vessels calcification (12). In addition, there are pieces of evidence regarding the association between cardiovascular diseases and vitamin D deficiency (45). However, despite evidence regarding the cardioprotection role of vitamin $\mathrm{D}$, there is still no causal effect between vitamin $\mathrm{D}$ deficiency and chronic cardiovascular diseases (46). Low levels of vitamin $\mathrm{D}$ can also be correlated with higher coronary artery calcification scores, inflammation, impaired endothelial function and increased vascular stiffness (47). Moreover, it has been confirmed that patients having cerebrovascular disease, associated musculoskeletal diseases, stroke and arterial hypertension could be considered as a highrisk group for vitamin D deficiency. Thus, evaluation of vitamin $\mathrm{D}$ level in these patients is a suitable suggestion (48). Besides the association of vitamin D deficiency with kidney dysfunction and inflammation as well as arterial hypertension, there are also supporting documents that show low levels of vitamin D could also be related with other classic cardiovascular risk factors such as obesity, physical inactivity and type I and II diabetes (49).

\section{Chronic liver diseases and vitamin D deficiency}

Vitamin D could also influence the progress of chronic liver disease (50). It has reported that vitamin D deficiency could associate with the severity of chronic liver disease while supplementation of vitamin $\mathrm{D}$ can be helpful in the treatment of liver disease (51). Accordingly, patients with vitamin $\mathrm{D}$ deficiency are more prone to chronic liver disease, because of the severity of impaired synthesis of some proteins as well as severe liver damage (52). Moreover, hepatitis $\mathrm{C}$ virus (HCV) may play an important role in not only inhibition of synthesis of $25(\mathrm{OH}) \mathrm{D}$ through fat metabolism but also prevention of producing of pre-vitamin D (53). On the other hand, vitamin D deficiency may be related to the severity of chronic liver disease and fibrosis in chronic hepatitis C (CHC) (54). Furthermore, vitamin $\mathrm{D}$ can be acted as an independent prognostic factor in chronic liver diseases. These findings indicated that vitamin $\mathrm{D}$ levels may decrease with the progression of liver cirrhosis (51).

\section{Vitamin D deficiency and autoimmune diseases}

Autoimmune diseases may occur through disturbance of body's immune system (12). The effect of immune regulatory activity of vitamin $\mathrm{D}$ on both adaptive or innate immune systems has been confirmed (55). Moreover, research has confirmed that vitamin D could act as a neurosteroid (56) and is required for the normal development of the brain and its function (56). In addition, the active form of vitamin D may have immunomodulatory effects on immune system cells especially $\mathrm{T}$ lymphocytes and cytokines (57). The prevalent autoimmune diseases may include MS, rheumatoid arthritis, type 1 diabetes mellitus and Crohn's disease (58), amyotrophic lateral sclerosis, Parkinson's and Alzheimer's diseases as well as neurocognitive disease (59), and patients who are at risk fractures (such as hips, shoulders, and spine) (60) and inflammatory bowel diseases (IBD) are prone to vitamin D deficiency (61). Graves' disease (GD) is another autoimmune disease with hyperthyroidism secondary to circulating autoantibodies causing by multiple factors such as genetic and environmental factors which vitamin $\mathrm{D}$ deficiency may have a role in extension of disease (62). Likewise, the deficiency of vitamin D may have an impact on the onset and progression of Graves' disease while intake of vitamin D supplement may improve the disease (62). It has been reported that vitamin D supplementation not only could prevent developing of autoimmune diseases but could also apply for their treatment (55). For 
neurological diseases, it has been suggested that optimal levels of vitamin $\mathrm{D}$ in the bloodstream are also needed to preserve the neurological development as well as to protect the brain (59).

It has also reported that sufficient vitamin $\mathrm{D}$ could be a necessary factor to prevent osteoporosis and might diminish the hazard of conditions unrelated to mineral metabolism and bone diseases. Additionally supplementation of calcium could not be considered as the main treatment of osteoporosis and more research is necessary to identify the minimum required daily dose of vitamin D supplementation (63).

\section{Treatment of vitamin $\mathrm{D}$ deficiency}

To cope with vitamin D deficiency, there are different recommendations. The daily intake of vitamin $\mathrm{D}$ is one of the most important methods, but it seems that higher amounts would be required to have better preventive or treatment effects (2). Another method would be the exposure to sunlight (64). It has been reported that sunlight could have a positive effect on mortality originated from cancers of colon, prostate and breast (65). However, sunlight exposure may lead to various risks such as skin ageing, inflammation and even cancer (66). Sunlight exposure plays an important role to improve vitamin D status other than oral supplementation with the advantage of prevention from vitamin $\mathrm{D}$ intoxication as well as disadvantage of erythema based on wavelength and duration of exposure (2). Intake of vitamin D supplements is another recommendation. In a randomized controlled trial, a three-mouth consumption of low-fat yogurt with supplementing of vitamin D-fortified had a positive effect on quality of life indices in diabetic postmenopausal women (67). It has been reported that cholecalciferol (vitamin D3) is mainly stronger than vitamin D2 (ergocalciferol) as well as the fact that the safe higher intake level for vitamin D3 would be 10000 IU/d (68). However, there is an uncertainty about the preventive effect of vitamin $\mathrm{D}$ on diseases. It is recommended that high-risk people are better to have sunlight exposure and diet as well as low dose vitamin D supplements (400-800 IU/d) as an individual basis. However, current evidence could not support the consumption of vitamin D supplementation to preclude diseases (69).

\section{Conclusion}

In conclusion, vitamin D deficiency was only limited to rickets in the children and bone related disorders in adults in the past. However, nowadays it has also been associated with the pathogenesis and/or progression of many other diseases such as hypertension, MS, diabetes, cancer, and kidney disease. Despite this close relationship of vitamin $\mathrm{D}$ deficiency with various diseases, vitamin $\mathrm{D}$ insufficiency is not widely recognized as a problem by people, especially patients and physicians as well as health policy makers. It is recommended to conduct further studies on this association to clarify the exact effect of vitamin D deficiency as well as supplement therapy with vitamin $\mathrm{D}$ on human diseases.

Author's contribution

$\mathrm{ND}, \mathrm{SB}, \mathrm{MD}, \mathrm{MRK}, \mathrm{ZK}$ and AHD searched the literature and gathered the data. MA prepared the primary draft. MB completed the paper. MA finalized the manuscript. All authors read and signed the final manuscript.

\section{Conflicts of interest}

The authors declared no competing interests.

\section{Ethical considerations}

Ethical issues (including plagiarism, data fabrication, double publication) have been completely observed by the authors.

\section{Funding/Support}

This study was funded by Vice Chancellor of Research Affairs of Ahvaz Jundishapur University of Medical Sciences.

\section{References}

1. Arnson Y, Amital H, Shoenfeld Y. Vitamin D and autoimmunity: new aetiological and therapeutic considerations. Ann Rheum Dis. 2007;66:1137-42. doi: 10.1136/ard.2007.069831.

2. Zhang R, Naughton DP. Vitamin D in health and disease: current perspectives. Nutr J. 2010;9:65. doi: 10.1186/14752891-9-65.

3. Carlberg C. Current understanding of the function of the nuclear vitamin D receptor in response to its natural and synthetic ligands. Recent Results Cancer Res. 2003;164:2942.

4. Nagpal S, Na S, Rathnachalam R. Noncalcemic actions of vitamin D receptor ligands. Endocr Rev. 2005;26:662-87. doi:10.1210/er.2004-0002.

5. Amano Y, Komiyama K, Makishima M. Vitamin D and periodontal disease. J Oral Sci. 2009;51:11-20.

6. Russell JA. Osteomalacic myopathy. Muscle Nerve. 1994;17:578-80. doi: 10.1002/mus.880170603.

7. Bordelon P, Ghetu MV, Langan RC. Recognition and management of vitamin D deficiency. Am Fam Physician. 2009;80:841-6.

8. Wortsman J, Matsuoka LY, Chen TC, Lu Z, Holick MF. Decreased bioavailability of vitamin D in obesity. Am J Clin Nutr. 2000;72:690-3.

9. Coccia P, Blazquez J, Contreras M, Ferrais V, Raddavero C, Ghezzi L, et al. High prevalence of vitamin D deficiency among children with chronic kidney disease and kidney transplant. Arch Argent Pediatr. 2017;115:220-6. doi: 10.5546/aap.2017.eng.220.

10. Barchetta I, Cimini FA, Cavallo MG. Vitamin D supplementation and non-alcoholic fatty liver disease: present and future. Nutrients. 2017;9. pii: E1015. doi: $10.3390 /$ nu9091015.

11. Tangpricha V, Pearce EN, Chen TC, Holick MF. Vitamin D insufficiency among free-living healthy young adults. Am J Med. 2002;112:659-62. 
12. Solanki P, Gohil P. Role of vitamin d in human diseases and disorders - an overview. Int J Pharmacol Res. 2014;4:34-42.

13. Barker DJ, Winter PD, Osmond C, Margetts B, Simmonds SJ. Weight in infancy and death from ischaemic heart disease. Lancet. 1989;2:577-80.

14. Hart PH, Lucas RM, Walsh JP, Zosky GR, Whitehouse AJ, Zhu K, et al. Vitamin D in fetal development: findings from a birth cohort study. Pediatrics. 2015;135:e167-73. doi: 10.1542/peds.2014-1860.

15. Tiwari P, Sharma N. Role of Vitamin D in Various Illnesses: A Review. J Pharma Care Health Sys. 2017;4:3. doi: 10.4172/2376-0419.1000176.

16. Theodoratou E, Tzoulaki I, Zgaga L, Ioannidis JP. Vitamin $\mathrm{D}$ and multiple health outcomes: umbrella review of systematic reviews and meta-analyses of observational studies and randomised trials. BMJ. 2014;348:g2035. doi: 10.1136/bmj.g2035.

17. Miyake Y, Sasaki S, Tanaka K, Hirota Y. Dairy food, calcium and vitamin D intake in pregnancy, and wheeze and eczema in infants. Eur Respir J. 2010;35:1228-34. doi: 10.1183/09031936.00100609.

18. Wang TJ, Pencina MJ, Booth SL, Jacques PF, Ingelsson E, Lanier $\mathrm{K}$, et al. Vitamin D deficiency and risk of cardiovascular disease. Circulation. 2008;117:503-11. doi: 10.1161/CIRCULATIONAHA.107.706127.

19. Amiri M. Vitamin D and cancer; a contradictory problem. Immunopathol Persa. 2018;4:e13.

20. Tournis S, Mitrakou A. The effects of calcium and vitamin D supplementation on blood glucose and markers of inflammation in nondiabetic adults: response to Pittas et al. Diabetes Care. 2007;30:e81. doi:10.2337/dc07-0665.

21. Amiri M. Age at menarche and vitamin D; a new perspective of an old problem. Ann Res Antioxid. 2016;1:e28.

22. Myhr KM. Vitamin D treatment in multiple sclerosis. J Neurol Sci. 2009;286:104-8. doi: 10.1016/j.jns.2009.05.002.

23. Melamed ML, Michos ED, Post W, Astor B. 25-hydroxyvitamin D levels and the risk of mortality in the general population. Arch Intern Med. 2008;168:1629-37. doi: $\quad$ 10.1001/archinte.168.15.1629.

24. Zgaga L, Theodoratou E, Farrington SM, Agakov F, Tenesa A, Walker M, et al. Diet, environmental factors, and lifestyle underlie the high prevalence of vitamin D deficiency in healthy adults in Scotland, and supplementation reduces the proportion that are severely deficient. J Nutr. 2011;141:1535-42. doi: 10.3945/jn.111.140012.

25. Echida Y, Mochizuki T, Uchida K, Tsuchiya K, Nitta K. Risk factors for vitamin $\mathrm{D}$ deficiency in patients with chronic kidney disease. Intern Med. 2012;51:845-50.

26. Shoben AB, Rudser KD, de Boer IH, Young B, Kestenbaum B. Association of oral calcitriol with improved survival in nondialyzed CKD. J Am Soc Nephrol. 2008;19:1613-9. doi: 10.1681/ASN.2007111164.

27. Tonelli M, Wiebe N, Culleton B, House A, Rabbat C, Fok $\mathrm{M}$, et al. Chronic kidney disease and mortality risk: a systematic review. J Am Soc Nephrol. 2006;17:2034-47. doi: 10.1681/ASN.2005101085.

28. Inda Filho AJ, Melamed ML. Vitamin D and Kidney Disease. What we know and what we do not know. J Bras Nefrol. 2013;35:323-31. doi: 10.5935/0101-2800.20130051.

29. de Zeeuw D, Agarwal R, Amdahl M, Audhya P, Coyne D, Garimella T, et al. Selective vitamin D receptor activation with paricalcitol for reduction of albuminuria in patients with type 2 diabetes (VITAL study): a randomised controlled trial. Lancet. 2010;376:1543-51. doi: 10.1016/ S0140-6736(10)61032-X.

30. Hushmand M, Behmanesh F, Ahanchian H, Khalesi M, Ataei A. Vitamin D and respiratory disorder. Rev Clin Med. 2015;2:195-9. doi:10.17463/RCM.2015.04.008.

31. Jung JY, Kim YS, Kim SK, Kim HY, Oh YM, Lee SM, et al. Relationship of vitamin D status with lung function and exercise capacity in COPD. Respirology. 2015;20:782-9. doi: 10.1111/resp.12538.

32. Cannell JJ, Vieth R, Umhau JC, Holick MF, Grant WB, Madronich S, et al. Epidemic influenza and vitamin D. Epidemiol Infect. 2006;134:1129-40. doi: 10.1017/ S0950268806007175.

33. Monadi M, Heidari B, Asgharpour M, Firouzjahi A, Monadi M, Ghazi Mirsaied MA. Relationship between serum vitamin $\mathrm{D}$ and forced expiratory volume in patients with chronic obstructive pulmonary disease (COPD). Caspian J Intern Med. 2012;3:451-5.

34. Finklea JD, Grossmann RE, Tangpricha V. Vitamin D and chronic lung disease: a review of molecular mechanisms and clinical studies. Adv Nutr. 2011;2:244-53. doi: 10.3945/ an. 111.000398

35. Kunisaki KM, Niewoehner DE, Singh RJ, Connett JE. Vitamin D status and longitudinal lung function decline in the Lung Health Study. Eur Respir J. 2011;37:238-43. doi: 10.1183/09031936.00146509.

36. Yumrutepe $\mathrm{T}$, Aytemur ZA, Baysal $\mathrm{O}$, Taskapan $\mathrm{H}$, Taskapan CM, Hacievliyagil SS. Relationship between vitamin $\mathrm{D}$ and lung function, physical performance and balance on patients with stage I-III chronic obstructive pulmonary disease. Rev Assoc Med Bras. 2015;61:132-8. doi: 10.1590/1806-9282.61.02.132.

37. Said AF, Abd-Elnaeem EA. Vitamin D and chronic obstructive pulmonary disease. Egypt J Chest Dis Tuberc. 2015;64:67-73. doi: 10.1016/j.ejcdt.2014.11.033.

38. Holick MF. Vitamin D deficiency. N Engl J Med. 2007;357:26681. doi: 10.1056/NEJMra070553.

39. Moosavi SAJ, Shoushtari MH. The effects of vitamin D supplementation on pulmonary function of chronic obstructive pulmonary disease patients, before and after clinical trial. Diseases. 2015;3:253-59. doi: 10.3390/ diseases3040253.

40. Gilbert CR, Arum SM, Smith CM. Vitamin D deficiency and chronic lung disease. Can Respir J. 2009;16:75-80.

41. Upadhyay Animesh A, Bhide Poorva P. Calcium and Vitamin D deficiency in Otolaryngological Diseases. Int J Med Res Health Sci. 2016;5:271-5.

42. Mosca L, Barrett-Connor E, Wenger NK. Sex/gender differences in cardiovascular disease prevention: what a difference a decade makes. Circulation. 2011;124:2145-54. doi: $\quad$ 10.1161/CIRCULATIONAHA.110.968792.

43. Lloyd-Jones DM, Larson MG, Beiser A, Levy D. Lifetime risk of developing coronary heart disease. Lancet. 1999;353:89-92. doi: 10.1016/S0140-6736(98)10279-9.

44. Kones R. Primary prevention of coronary heart disease: integration of new data, evolving views, revised goals, and role of rosuvastatin in management. A comprehensive survey. Drug Des Devel Ther. 2011;5:325-80. doi: 10.2147/ DDDT.S14934.

45. Giovannucci E, Liu Y, Hollis BW, Rimm EB. 25-hydroxyvitamin D and risk of myocardial infarction in 
men: a prospective study. Arch Intern Med. 2008;168:117480. doi: 10.1001/archinte.168.11.1174.

46. Schnatz PF, Manson JE. Vitamin D and cardiovascular disease: an appraisal of the evidence. Clin Chem. 2014;60:600-9. doi: 10.1373/clinchem.2013.211037.

47. Kunadian V, Ford GA, Bawamia B, Qiu W, Manson JE. Vitamin D deficiency and coronary artery disease: a review of the evidence. Am Heart J. 2014;167:283-91. doi: 10.1016/j.ahj.2013.11.012.

48. Kienreich K, Grübler M, Tomaschitz A, Schmid J, Verheyen $\mathrm{N}$, Rutters $\mathrm{F}$, et al. Vitamin D, arterial hypertension \& cerebrovascular disease. Indian J Med Res. 2013;137:66979.

49. Muscogiuri G, Sorice GP, Ajjan R, Mezza T, Pilz S, Prioletta A, et al. Can vitamin D deficiency cause diabetes and cardiovascular diseases? Present evidence and future perspectives. Nutr Metab Cardiovasc Dis. 2012;22:81-7. doi: 10.1016/j.numecd.2011.11.001.

50. Foroughi M, Maghsoudi Z, Ghiasvand R, Iraj B, Askari G. Effect of Vitamin D Supplementation on C-reactive Protein in Patients with Nonalcoholic Fatty Liver. Int J Prev Med. 2014;5:969-75.

51. Mozaffari HM, Abbasi HA, Goshayesh L, Esmaeelzadeh A, Bahari A, Mokhtarifar A, et al. Effect of vitamin D supplementation on chronic liver disease: systematic literature review. Rev Clin Med. 2017;4:14-19. doi:10.22038/ RCM.2016.7487.

52. Nair S. Vitamin D deficiency and liver disease. Gastroenterol Hepatol(NY). 2010;6:491-3.

53. Webb AR. Who, what, where and when-influences on cutaneous vitamin D synthesis. Prog Biophys Mol Biol. 2006;92:17-25. doi: 10.1016/j.pbiomolbio.2006.02.004.

54. Baur K, Mertens JC, Schmitt J, Iwata R, Stieger B, Eloranta $\mathrm{JJ}$, et al. Combined effect of 25-OH vitamin D plasma levels and genetic vitamin D receptor (NR 1I1) variants on fibrosis progression rate in HCV patients. Liver Int. 2012;32:63543. doi: 10.1111/j.1478-3231.2011.02674.x.

55. Szodoray P, Nakken B, Gaal J, Jonsson R, Szegedi A, Zold E, et al. The complex role of vitamin $D$ in autoimmune diseases. Scand J Immunol. 2008;68:261-9. doi: 10.1111/j.13653083.2008.02127.x.

56. Groves NJ, McGrath JJ, Burne TH. Vitamin D as a neurosteroid affecting the developing and adult brain. Annu Rev Nutr. 2014;34:117-41. doi: 10.1146/annurevnutr-071813-105557.
57. Marques CD, Dantas AT, Fragoso TS, Duarte AL. The importance of vitamin D levels in autoimmune diseases. Rev Bras Reumatol. 2010;50:67-80.

58. Holick MF. Vitamin D: importance in the prevention of cancer, type 1 diabetes, heart disease, and osteoporosis. Am J Clin Nutr. 2004;79:362-71.

59. Di Somma C, Scarano E, Barrea L, Zhukouskaya VV, Savastano S, Mele C, et al. Vitamin D and Neurological Diseases: An Endocrine View. Int J Mol Sci. 2017;18. pii: E2482. doi: 10.3390/ijms18112482.

60. Özdemir ZT, Özkan EA, Akkoca AO, Ekim M, Börekçi E, Ylldırım T, et al. Osteoporosis and Vitamin D Deficiency in Patients with Sickle Cell Disease. J Clin Anal Med. 2016;7:483-7.

61. Cantorna MT, Munsick C, Bemiss C, Mahon BD. 1,25-Dihydroxycholecalciferol prevents and ameliorates symptoms of experimental murine inflammatory bowel disease. J Nutr. 2000;130:2648-52.

62. Alhuzaim ON, Aljohani N. Effect of vitamin d 3 on untreated graves' disease with vitamin d deficiency. Clin Med Insights Case Rep. 2014;7:83-5. doi: 10.4137/CCRep.S13157.

63. Hanley DA, Cranney A, Jones G, Whiting SJ, Leslie WD, Cole DE, et al. Vitamin D in adult health and disease: a review and guideline statement from Osteoporosis Canada. CMAJ. 2010;182:E610-8. doi: 10.1503/cmaj.080663.

64. Holick MF. Sunlight and vitamin D for bone health and prevention of autoimmune diseases, cancers, and cardiovascular disease. Am J Clin Nutr. 2004;80:1678S-88S.

65. Giovannucci E, Liu Y, Rimm EB, Hollis BW, Fuchs CS, Stampfer MJ, et al. Prospective study of predictors of vitamin D status and cancer incidence and mortality in men. J Natl Cancer Inst. 2006;98:451-9.

66. Vondra K, Stárka L, Hampl R. Vitamin D and thyroid diseases. Physiol Res. 2015;64:S95-S100.

67. Jafari T, Amiri M. Effects of 3-mounth regular consumption of vitamin D-fortified low fat yogurt on quality of life indices in diabetic postmenopausal women: A randomised controlled clinical trial. Int J Epidemiol Res. 2016;3:139147.

68. Heaney RP. Vitamin D in health and disease. Clin J Am Soc Nephrol. 2008;3:1535-41. doi: 10.2215/CJN.01160308.

69. Bolland MJ, Avenell A, Grey A. Should adults take vitamin D supplements to prevent disease? BMJ. 2016;355:i6201. doi: $10.1136 /$ bmj.i6201.

Copyright (c) 2018 The Author(s); Published by Society of Diabetic Nephropathy Prevention. This is an open-access article distributed under the terms of the Creative Commons Attribution License (http://creativecommons.org/licenses/by/4.0), which permits unrestricted use, distribution, and reproduction in any medium, provided the original work is properly cited. 